\title{
Effect of Organophosphate Pesticides on the Activities of Lecithin-Cholesterol Acyltransferase and Cholinesterase in Rat Serum
}

\author{
Mitsuo Nakagawa,* Hayao Kobayashi, Mieko Katsuya, \\ Noriko TAKada, and SHoji KoJIMA \\ Faculty of Pharmaceutical Sciences, Kumamoto University, 5-1 \\ Ohe-Honmachi, Kumamoto, Kumamoto 862, Japan
}

(Received May 13, 1981)

\begin{abstract}
The lecithin-cholesterol acyltransferase activity in rat serum as well as that in human plasma was examined by using sonicated dispersions of lecithin and cholesterol mixtures as substrates.

When dispersions with molar ratios of 1.2 and 5.9 were used as substrates, the acyltransferase activity in rat serum, in contrast to that in human plasma, was greater with the substrate dispersion having a molar ratio of 1.2 than with that of 5.9. In addition, the acyltransferase activity in rat serum with the dispersion having a molar ratio of 0.9 was inhibited upon addition of increasing amounts of lecithin, but that in human plasma for the same dispersion was stimulated and the maximum acyltransferase activity was obtained at a molar ratio of approximately 7 .

On the basis of these results, the inhibitory actions of organophosphate pesticides on the acyltransferase and cholinesterase in rat serum were investigated. The acyltransferase activity in rat serum was inhibited by the addition of $1 \times 10^{-3} \mathrm{M}$ dimethyldichlorovinylphosphate (DDVP) and methylparathion. The decreased acyltransferase activity in rat serum was not restored by the addition of $1 \times 10^{-3} \mathrm{M}$ 2-pyridine aldoxime methiodide (PAM). Similarly, cholinesterase activity in rat serum was almost completely inhibited by the addition of $1 \times 10^{-5} \mathrm{M}$ DDVP. However, the decreased cholinesterase activity was restored by the addition of $1 \times 10^{-3} \mathrm{M}$ PAM.

In addition, the acyltransferase and cholinesterase activities in serum obtained from rats administered DDVP ( $35 \mathrm{mg} / \mathrm{kg}$ body) in vivo were inhibited to approximately $83-87 \%$ and $35-37 \%$ of those in control rat serum, respectively.
\end{abstract}

Keywords-_LCAT; cholinesterase; DDVP; methylparathion; rat serum

Human plasma and rat serum contain cholinesterase [EC 3.1.1.8] and lectihin-cholesterol acyltransferase [EC 2.3.1.43] (LCAT), which catalyzes the formation of cholesterol ester from lecithin and cholesterol. ${ }^{1,2)}$ Since plasma cholinesterase is well known to be inhibited by oraganophosphate pesticides, plasma cholinesterase activity has often been used as a marker of in vivo organophosphate toxicity. ${ }^{3)}$ On the other hand, we reported previously that, with sonicated dispersions of lecithin and cholesterol mixture as substrates, the acyltransferase in human plasma was also inhibited by organophosphate pesticides in vitro. ${ }^{\mathbf{4}}$

In this work, we investigated the esterification of cholesterol in sonicated dispersions of lecithin and cholesterol mixture by rat serum and also the effects of organophosphate pesticides on the acyltransferase and cholinesterase activities in rat serum.

\section{Experimental}

Materials- - ${ }^{3} \mathrm{H}$-Cholesterol was purchased from New England Nuclear Corp. (Boston, Mass., U.S.A.) and purified by the same procedure as described previously.5) PAM was obtained from Sigma Chemical Co. (St. Louis, Mo., U.S.A.). Dimethyldichlorovinylphosphate (DDVP) and methylparathion were obtained from Wako Pure Chemical Ind. (Osaka, Japan). Lecithin was prepared from egg yolk by the method of Faure and purified by silicic acid column chromatography. Thin-layer chromatography of the purified lecithin on silica gel $\mathrm{G}$ plates in chloroform-methanol-water $(65: 25: 4, \mathrm{v} / \mathrm{v})$ gave a single spot of lecithin.

Preparation of the Enzyme - - Human plasma was obtained from outdated human blood containing 0.15 volume of anticoagulant solution (glucose, citric acid and sodium citrate) by centrifugation and was 
then dialyzed against sodium phosphate buffer, $\mathrm{pH} 7.4$, ionic strength 0.1 . Rat serum was prepared from male albino rats of the Wistar strain, weighing $150-180 \mathrm{~g}$, which had been fed ad libitum on a commercial diet obtained from Oriental Yeast Co. (Tokyo, Japan). To test the effect of DDVP, rats were divided into two groups, and given orally $0.3 \mathrm{ml}$ of glycerol and $0.3 \mathrm{ml}$ of glycerol containing DDVP ( $35 \mathrm{mg} / \mathrm{kg}$ body), respectively. At $2 \mathrm{~h}$ after the administration, serum samples were obtained from these rats. Human plasma and rat serum used for the enzyme assay were diluted with phosphate buffer to give a protein content of $60 \mathrm{mg}$ per mI.

Enzyme Assay - Sonicated dispersions of lecithin and cholesterol mixtures as substrates were prepared as described previously.7) The incubation mixture for the assay of LCAT activity contained $0.1 \mathrm{ml}$ of the substrate dispersion and $0.2 \mathrm{ml}$ of human plasma or rat serum. The final volume was adjusted to $0.5 \mathrm{ml}$ with phosphate buffer, $\mathrm{pH}$ 7.4. The various materials added to the incubation medium are described elsewhere in the text. The samples were placed in $15 \mathrm{ml}$ screw-capped tubes, which were flushed with $\mathrm{N}_{2}$, sealed and incubated for $3 \mathrm{~h}$ at $37^{\circ} \mathrm{C}$ with mechanical shaking. After incubation, extraction and separation of lipids and measurements of radioactivity, protein content, cholesterol content and lipid phosphorus were determined as described previously. $\left.{ }^{7}\right)$

Rat serum cholinesterase activity was determined by the procedure of Okui et al.8) based on the spectrophotometric method of Hesterin ${ }^{\text {() }}$ as described previously. ${ }^{10}$ )

\section{Results and Discussion}

Figure 1 shows the extent of cholesterol esterification at various times of incubation by $0.4 \mathrm{ml}$ of rat serum per $\mathrm{ml}$ of the incubation medium. The esterification activity for the dispersion with a lecithin/cholesterol molar ratio of 1.2 increased linearly for up to $3 \mathrm{~h}$. Therefore, sonicated dispersions of lecithin and cholesterol mixtures can be used as substrates for the acyltransferase in rat serum as well as that in human plasma.

On the other hand, the esterification of cholesterol in sonicated dispersions of lecithin and cholesterol mixtures by human plasma ${ }^{11)}$ and/or residual protein fraction $(d>1.210 \mathrm{~g} /$ $\mathrm{cm}^{3}$ ) of human plasma') was remarkably affected by lecithin content in the dispersions; that is, the maximum esterification by the residual protein fraction of human plasma was obtained

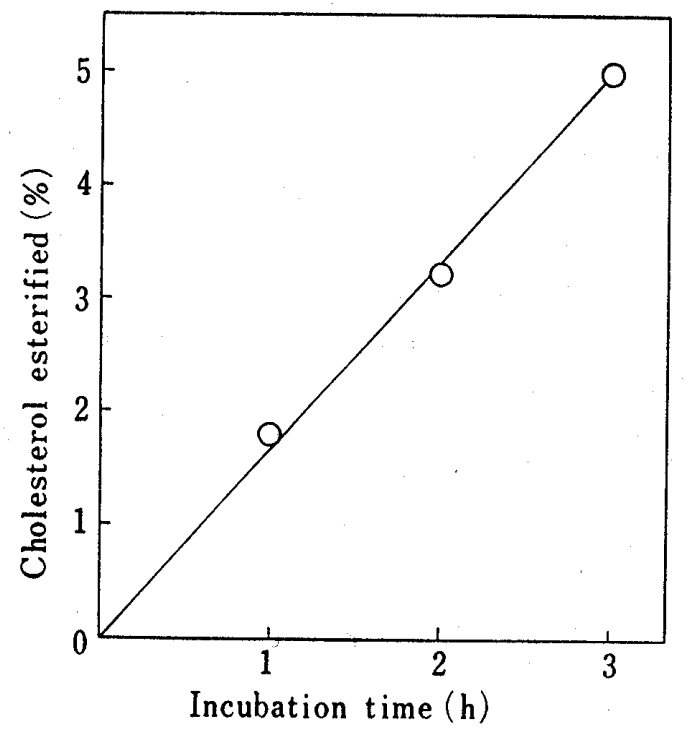

Fig. 1. Time Course of Cholesterol Esterification in Rat Serum

The incubation mixture contained $0.1 \mathrm{ml}$ of substrate dispersion (lecithin/cholesterol molar ratio of 1.2 ) and $0.2 \mathrm{ml}$ of rat serum (12 $\mathrm{mg}$ protein/ incubation medium). The final volume was adjusted to $0.5 \mathrm{ml}$ with phosphate buffer, $\mathrm{pH} 7.4$, ionic strength 0.1 . Incubation was carried out at $37^{\circ} \mathrm{C}$. The radioactivity and amount of free cholesterol added to the incubation medium as a dispersion were $0.2 \mu \mathrm{ci} / 0.12 \mu \mathrm{mol} / \mathrm{ml}$ of incubation medium.

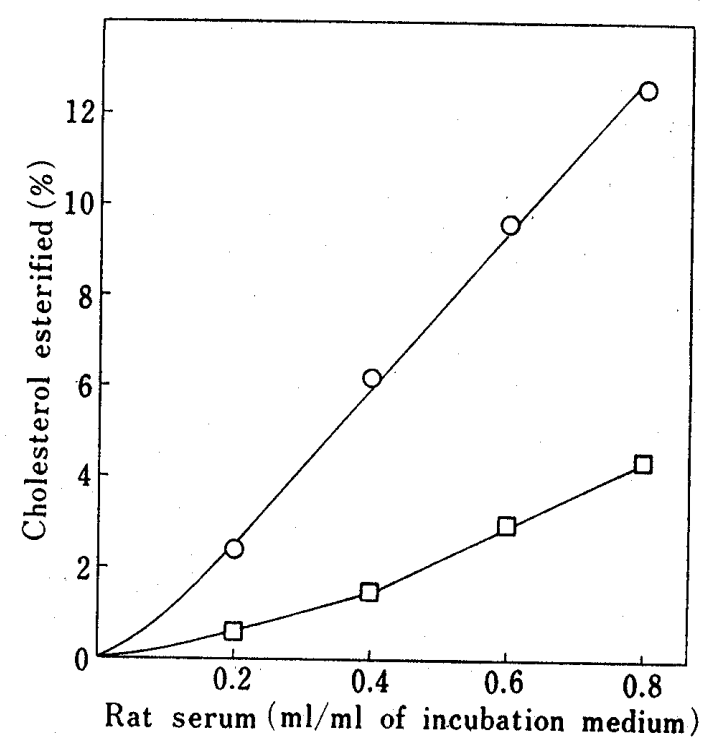

Fig. 2. Effect of Lecithin Concentration on Cholesterol Esterification by Various Amounts of Rat Serum

The incubation conditions were the same as in Fig. 1 except for the use of substrate dispersion with a molar ratio of 5.9 and an incubation time of $3 \mathrm{~h}$. The radioactivity and amount of free cholesterol in the dispersion with a molar ratio of 5.9 were $0.2 \mu \mathrm{ci} / 0.12$ $\mu \mathrm{mol} / \mathrm{ml}$ of incubation medium.

$O$ : substrate dispersion with a molar ratio of 1.2 .

$\square$ : substrate dispersion with a molar ratio of 5.9 . 
when the weight ratio of lecithin to $\mathrm{HDL}_{3}$ protein $\left(1.125<d<1.210 \mathrm{~g} / \mathrm{cm}^{3}\right.$, high density lipoproteins) was $3.7-4.2$. Therefore, the extents of esterification of cholesterol in the dispersions with lecithin/cholesterol molar ratios of 1.2 and 5.9 by various amounts of rat serum were compared. As shown in Fig. 2, the esterification of cholesterol in both dispersions progressively increased upon addition of increasing amounts of rat serum. The extent of cholesterol esterification was higher for the dispersion with a molar ratio of 1.2 than for that of 5.9. This result was incompatible with our previous observation that the acyltransferase activity in human plasma for a dispersion with a lecithin/cholesterol molar ratio of 5.9 was higher than

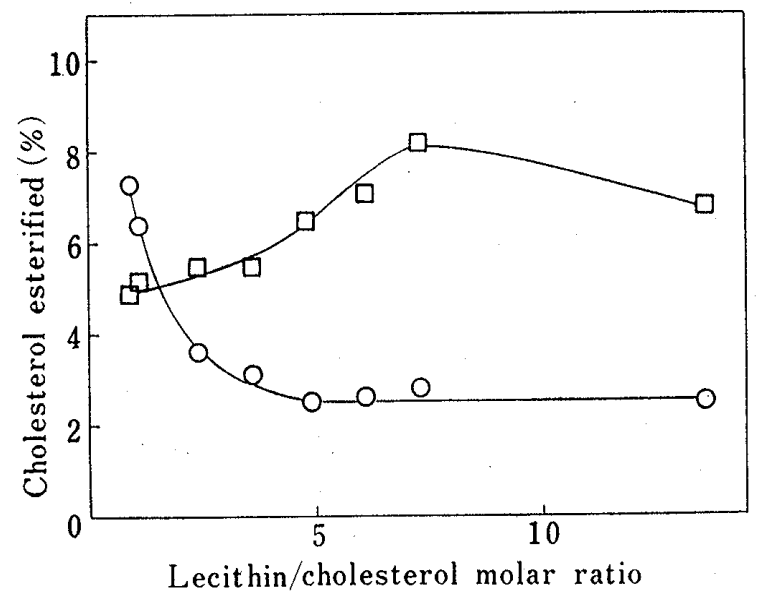

Fig. 3. Effects of Lecithin Concentration on Cholesterol Esterification by Rat Serum and Human Plasma

The incubation conditions were the same as in Fig. 1 except for the use of dispersion with a molar ratio of 0.9 and an incubation time of $3 \mathrm{~h}$. Lecithin was added to the incubation medium as a dispersion prepared by the same procedure as the substrate dispersion.

The radioactivity and amount of free cholesterol in the dispersion with a molar ratio of 0.9 were $0.2 \mu \mathrm{ci} / 0.15$ $\mu \mathrm{mol} / \mathrm{ml}$ of incubation medium.

$O$ : rat serum, $\square$ : human plasma. that for a dispersion with a molar ratio of 1.2.11) Thus, we further investigated the discrepancy between the acyltransferase activities in rat serum and in human plasma for the dispersions with low and high molar ratios of lecithin to cholesterol. As shown in Fig. 3, the acyltransferase activity in rat serum with the dispersion having a molar ratio of 0.9 was higher than that in human plasma and also was inhibited upon addition of increasing amounts of lecithin. In contrast, the acyltransferase activity in human plasma was stimulated upon addition of increasing amounts of lecithin and the maximum activity was obtained at a molar ratio of approximately 7. Accordingly, the discrepancy between the acyltransferase activities in rat serum and in human plasma with the dispersions with low (1.2) and high (5.9) molar ratios of lecithin to cholesterol may be mainly attributed to the weight ratio of lecithin to HDL protein $(1.063<d<1.210$ $\left.\mathrm{g} / \mathrm{cm}^{3}\right)$, because the $\mathrm{HDL}_{3}$ content in rat serum (approximately $120 \mathrm{mg} / 100 \mathrm{ml}$ ) is lower than that in human plasma (approximately $230 \mathrm{mg} / 100 \mathrm{ml}) .^{12}$ ) We have also found that the amount of exogenous HDL protein required for the maximum acyltransferase activity in rat serum may be larger than that in human plasma.

Accordingly, these results suggest that substrate dispersion having a low molar ratio of lecithin to cholesterol rather than that having a high molar ratio of lecithin to cholesterol should be used as a substrate for the measurement of the acyltransferase activity in rat serum.

On the basis of the observations mentioned above, we investigated the effect of organophosphate pesticides on the acyltransferase activities in rat serum and human plasma. As shown in Table $I$, the acyltransferase activity in human plasma was inhibited by organophosphate pesticides in accord with the results reported previously by us. ${ }^{4}$ The inhibitory action of DDVP and methylparathion on the acyltransferase activity in human plasma was greater for the dispersion with a molar ratio of 1.2 than for that of 5.9. The results suggest that the increase of lecithin content in the dispersion may protect the enzyme against the inhibitory action of organophosphate pesticides. Similarly, the acyltransferase activity in rat serum was inhibited at concentrations of $1 \times 10^{-4} \mathrm{M}$ DDVP and $5 \times 10^{-4} \mathrm{M}$ methylparathion and was reduced to approximately $6-15 \%$ and $23 \%$ of the control level by the addition of $1 \times 10^{-3} \mathrm{M}$ DDVP and methylparathion, respectively. The inhibitory potency of DDVP was higher than that of methylparathion, which was the same as the result obtained with human plasma. Also, the extents of inhibition by DDVP and methylparathion of the activity in rat serum with the dispersion having a molar ratio of 1.2 were comparable to those 
TABLE I. Effect of Organophosphate Pesticides on LCAT in Rat Serum and Human Plasma

\begin{tabular}{|c|c|c|c|c|}
\hline \multirow{3}{*}{ Addition } & & \multicolumn{2}{|c|}{ Cholesterol esterified $(\%)$} & \\
\hline & \multicolumn{2}{|c|}{ Rat serum } & \multicolumn{2}{|c|}{ Human plasma } \\
\hline & $\mathrm{L} / \overparen{C=1.2}$ & $\bar{L} / \mathrm{C}=1.2$ & $\mathrm{~L} / \overparen{C=1.2}$ & $\mathrm{~L} / \mathrm{C}=\mathbf{5 . 9}$ \\
\hline None & $4.7(100)$ & $1.3(100)$ & $3.7(100)$ & $5.1(100)$ \\
\hline $\operatorname{DDVP}\left(1 \times 10^{-4} \mathrm{M}\right)$ & $2.5(53.2)$ & $0.7(53.8)$ & - & - \\
\hline$\left(5 \times 10^{-4} \mathrm{M}\right)$ & $0.6(12.8)$ & $0.4(30.8)$ & - & 一 \\
\hline$\left(1 \times 10^{-3} \mathrm{M}\right)$ & $0.3(6.4)$ & $0.2(15.4)$ & $0.4(10.8)$ & $1.5(29.4)$ \\
\hline \multicolumn{5}{|l|}{ Methylparathion } \\
\hline$\left(1 \times 10^{-4} \mathrm{M}\right)$ & $4.4(93.6)$ & $1.3(100)$ & - & - \\
\hline$\left(5 \times 10^{-4} \mathrm{M}\right)$ & $2.1(44.7)$ & $0.6(46.2)$ & - & - \\
\hline$\left(1 \times 10^{-3} \mathrm{M}\right)$ & $1.1(23.4)$ & $0.3(23.1)$ & $1.3(35.1)$ & $2.3(45.3)$ \\
\hline
\end{tabular}

The incubation conditions were the same as in Fig. 1 except for the addition of organophosphate pesticides and the use of $0.2 \mathrm{ml}$ of rat serum or human plasma. Each organophosphate pesticide was added as $20 \mu \mathrm{l}$ of ethanol solution $/ \mathrm{ml}$ of incubation medium. The reference sample contained 20 $\mu \mathrm{l}$ of ethanol $/ \mathrm{ml}$ of incubation medium. The values in parentheses are percentages of the values obtained in the absence of organophosphate pesticide. L/C: lecithin/cholesterol molar ratio.

obtained in human plasma with the same dispersion.

On the other hand, the inhibitory effect of organophosphate pesticides on human plasma cholinesterase is well known to be due to the phosphorylation of the serine hydroxyl residue in the enzyme active center ${ }^{13)}$ and is also known to be eliminated by the addition of PAM. ${ }^{8,10}$ Therefore, we investigated the effect of PAM on the acyltransferase and cholinesterase activities in rat serum in the presence of organophosphate pesticides. As shown in Table II, cholinesterase activity in rat serum was almost completely inhibited by the addition of $1 \times 10^{-5} \mathrm{M}$ DDVP. The decreased cholinesterase activity in the presence of DDVP was restored to approximately $52-58 \%$ of the control level by the addition of $1 \times 10^{-3} \mathrm{M}$ PAM. However,

TABLE II. Effects of PAM on LCAT and Cholinesterase Activities in Rat Serum in the Presence of Organophosphate Pesticides

\begin{tabular}{|c|c|c|c|c|}
\hline \multirow{3}{*}{ Addition } & \multicolumn{4}{|c|}{ Cholesterol esterified ( $\%)$} \\
\hline & \multicolumn{2}{|c|}{ Expt. I } & \multicolumn{2}{|c|}{ Expt. II } \\
\hline & - PAM & + PAM & $-\mathrm{PAM}$ & $+\mathrm{PAM}$ \\
\hline None & $5.9(100)$ & $6.3(100)$ & $4.5(100)$ & $5.0(100)$ \\
\hline $\operatorname{DDVP}\left(1 \times 10^{-4} \mathrm{M}\right)$ & $3.0(50.8)$ & $4.0(63.5)$ & $3.1(68.9)$ & $4.0(80.0)$ \\
\hline$\left(5 \times 10^{-4} M\right)$ & $1.0(16.9)$ & $1.4(22.2)$ & $1.6(35.6)$ & $1.8(36.0)$ \\
\hline$\left(1 \times 10^{-3} \mathrm{M}\right)$ & $0.6(10.2)$ & $0.7(11.1)$ & $0.8(17.8)$ & $0.9(18.0)$ \\
\hline \multirow{5}{*}{$\begin{array}{l}\text { Methylparathion } \\
\begin{array}{r}\left(1 \times 10^{-4} \mathrm{M}\right) \\
\left(5 \times 10^{-4} \mathrm{M}\right) \\
\left(1 \times 10^{-3} \mathrm{M}\right)\end{array}\end{array}$} & & & & \\
\hline & $5.8(98.3)$ & $6.2(98.4)$ & $4.3(95.6)$ & $4.5(90.0)$ \\
\hline & $3.4(57.6)$ & $3.9(61.9)$ & $2.3(51.1)$ & $2: 8(56.0)$ \\
\hline & $1.7(28.8)$ & $2.3(36.5)$ & $1.6(35.6)$ & $1.8(36.0)$ \\
\hline & \multicolumn{4}{|c|}{ Cholinesterase activity ${ }^{a)}$} \\
\hline None & $19.4(100)$ & $18.7(100)$ & $25.1(100)$ & $17.5(100)$ \\
\hline $\operatorname{DDVP}\left(1 \times 10^{-5} \mathrm{M}\right)$ & 0 & $10.8(57.7)$ & $1.7(6.8)$ & $9.1(52.0)$ \\
\hline
\end{tabular}

The incubation conditions for the LCAT reaction were the same as in Fig. 2 except for the addition of organophosphate pesticides and PAM, and the use of $0.2 \mathrm{ml}$ of rat serum. Each organophosphate pesticide was added as $20 \mu l$ of ethanol solution/ml of incubation medium. The reference sample contained $20 \mu \mathrm{l}$ of ethanol/ml of incubation medium. Cholinesterase activity was determined by the method of Okui et al $^{8}{ }^{8}$ Rat serum for the assay contained $12 \mathrm{mg}$ protein/incubation medium. The concentration of PAM in the incubation medium was $1 \times 10^{-3} \mathrm{M}$.

a) [(Optical density of the incubation medium containing acetylcholine, rat serum and neostigmine)-(optical density of the incubation medium containing acetylcholine and rat serum with or without DDVP)] $\times 100$. 
TABLE III, LCAT and Cholinesterase Activities in Serum prepared from Rats exposed to DDVP in Vivo

\begin{tabular}{lllll}
\hline \hline \multirow{2}{*}{ Enzyme preparation } & \multicolumn{2}{c}{ Cholesterol esterified (\%) } & \multicolumn{2}{c}{ Cholinesterase activity } \\
& Expt. J & Expt. II & Expt. I & Expt. II \\
\hline Control rat & $4.5(100)$ & $6.4(100)$ & $33.2(100)$ & $32.1(100)$ \\
Rats exposed to DDVP & $3.9(86.7)$ & $5.3(82.8)$ & $11.6(34.9)$ & $11.9(37.1)$ \\
\hline
\end{tabular}

DDVP ( $35 \mathrm{mg} / \mathrm{kg}$ body) dissolved in $0.3 \mathrm{ml}$ of glycerol was administered orally to rats. At $2 \mathrm{~h}$ after the administration, rat serum was obtained. Control rats were administered $0.3 \mathrm{ml}$ of glycerol. The incubation conditions for the measurements of LCAT and cholinesterase activities were the same as in Table II.

the decreased acyltransferase activity in the presence of $1 \times 10^{-3} \mathrm{M}$ DDVP or methylparathion was not restored by the addition of $1 \times 10^{-3} \mathrm{M}$ PAM. These results were consistent with the observations obtained with human plasma. ${ }^{10}$ ) Therefore, as indicated in our previous paper, ${ }^{10}$ ) the inhibitory action of organophosphate pesticides on the acyltransferase may be different from that on cholinesterase.

We further investigated the alterations of the acyltransferase and cholinesterase activities in serum obtained from rats orally administered a relatively large amount of DDVP $(35 \mathrm{mg} / \mathrm{kg}$ body). As shown in Table III, the acyltransferase and cholinesterase activities in rat serum obtained after the administration of DDVP were also inhibited to approximately $83-87 \%$ and $35-37 \%$ of those in control rat serum, respectively. These findings were similar to the results obtained in the in vitro experiments (see Table II). Therefore, the acyltransferase was a much less sensitive biochemical marker of organophosphate toxicity than cholinesterase. Similar results have recently been reported by Davies and Holub, ${ }^{14}$ ) who observed that plasma cholinesterase activity in rats fed diets containing various low amounts of parathion was significantly reduced from that in rats fed control diet without parathion, whereas no significant alteration of the acyltransferase activity in plasma was observed when parathion was fed.

\section{References and Notes}

1) J.A. Glomset, J. Lipid Res., 9, 155 (1968).

2) E. Usdin, In "International Encyclopedia of Pharmacology and Therapeutics, Anticholinesterase Agents," Vol. 1, ed. by A.G. Karczmar, Pergamon Press, Oxford, 1970, p. 151.

3) World Health Organization (WHO), Sixteenth report of the WHO Expert Committee on Insecticides, World. Health Org. Tech. Rep. Ser., 356, 14 (1967).

4) M. Nakagawa and M. Uchiyama, Biochem. Pharmacol., 23, 1641 (1974).

5) M. Nakagawa and S. Kojima, J. Biochem., 80, 729 (1976).

6) M. Faure, Bull. Soc. Chim. Biol., 32, 503 (1950).

7) M. Nakagawa and T. Nishida, Biochim. Biophys. Acta, 296, 577 (1973).

8) S. Okui, S. Watanabe, and S. Hashimoto, Eiseikagaku, 9, 108 (1963).

9) S. Hesterin, J. Biol. Chem., 180, 249 (1949).

10) M. Nakagawa, H. Kobayashi, S. Kojima, A. Uemura, and M. Uchiyama, Chem. Pharm. Bull., 25, 2530 (1977).

11) M. Nakagawa, M. Takamura, and S. Kojima, J. Biochem., 81, 1011 (1977).

12) S. Eisenberg and R.I. Levy, In "Advances in Lipid Research," Vol. 13, ed. by R. Paoletti and D. Krichevsky, Academic Press, New York, 1975, p. 6.

13) E. Reiner and W.N. Aldridge, Biochem. J., 105, 171 (1967).

14) D.B. Davies and B.J. Holub, Toxicol. Appl. Pharmacol., 45, 641 (1978). 